\title{
Enrichment of Denitrifying Phosphate-accumulating Organisms in Nitrogen and Phosphorus Removal Process
}

\author{
Zijin QIN ${ }^{1, a}$, Liping Qiu ${ }^{1, b^{*}}$, Shoubin Zhang ${ }^{1, c}$, Jiabin Wang ${ }^{1, d}$, Kang Xie ${ }^{1, e}$ \\ ${ }^{1}$ School of Civil Engineering and Architecture, University of Jinan, No.336.West Road of Nan \\ Xinzhuang. Jinan. 250022, PR China \\ a979113907@qq.com, ${ }^{b}$ lipingqiu@163.com, ccea_zhangsb@ujn.edu.cn, \\ 'cea_wangjb@ujn.edu.cn, ${ }^{\mathrm{e}} \mathrm{cea}$ _xiek@ujn.edu.cn, \\ ${ }^{*}$ Corresponding Author
}

\begin{abstract}
Keywords: nitrogen and phosphorus removal process; denitrifying phosphorus-accumulating organisms; enrichment

Abstract. In this paper, a review on the mechanism of denitrifying phosphorus removal and the enrichment of denitrifying phosphorus-accumulating organisms in the process of nitrogen and phosphorus removal, such as $\mathrm{A}^{2} / \mathrm{O}$ and SBR, were presented, as well as the influence factors of enrichment were also carried out. And finally, the outlook of denitrifying phosphorus removal process for future research was suggested.
\end{abstract}

Conventional biological treatment process can effectively reduce $\mathrm{BOD}_{5}$ and $\mathrm{SS}$ of inflow, but the removal efficiencies of nitrogen and phosphorus in wastewater are not effective, which cause that a large amount of sewage containing nitrogen and phosphorus directly discharge into water body. Therefore, the nitrogen and phosphorus pollution is the primary cause for water entrophication. Although the government put forward more and more strictly requirements for sewage discharge, it is difficult to remove nitrogen and phosphorus efficiently for the conventional nitrogen and phosphorus removal process, because of various reasons, such as carbon-nitrogen ratio in the city sewage. So it is necessary to develop more stable, economical and efficient process for nitrogen and phosphorus removal.

Denitrifying phosphorus removal process is to complete domestication and enrichment of denitrifying phosphate-accumulating organisms (DNPAOs) by using anaerobic/anoxic alternate environment instead of the traditional anaerobic/aerobic environment. DNPAOs can use $\mathrm{NO}_{3}{ }^{-}$as electron acceptor in denitrifying phosphorus removal system, meanwhile through their metabolism complete excess phosphorus uptake and denitrification process at the same time to achieve the dual purpose of nitrogen and phosphorus removal. Application of denitrifying phosphorus removal process for treatment of municipal wastewater can not only save aeration quantity, but also reduce the amount of residual sludge. And it also can cut down investment and operation costs. In recent years, many scholars did a number of researches on denitrifying phosphorus removal technology. Due to the varying techniques, enrichment mode and denitrifying phosphorus removal degree, the conclusion was not entirely consistent.

\section{Mechanism of Denitrifying Phosphorus Removal}

In 1993, Kuba of Delft University observed in test [1] that in anaerobic/anoxic alternative operating conditions, a class of facultative anaerobic microorganisms can be enrichment. And the microorganisms can utilize $\mathrm{O}_{2}$ and $\mathrm{NO}_{3}{ }^{-}$as electron acceptor for denitrification and phosphorus uptake simultaneous. Two hypotheses were proposed to explain the above phenomenon. Two types of genus theory: There are two kinds of bacteria in biological phosphorus removal system, and one of them only use $\mathrm{O}_{2}$ as electron acceptor while another use $\mathrm{O}_{2}$ and $\mathrm{NO}_{3}{ }^{-}$or $\mathrm{NO}_{2}{ }^{-}$as electron acceptors for phosphorus uptake and denitrification simultaneously. One type of genus theory: There is only one species of bacteria in biological phosphorus removal system, which has a certain denitrification ability, the key lies in inducing denitrification enzyme under alternating anaerobic/anoxic operation 
environment, then denitrification phenomenon occur. They both have many supporters, but most researchers tend to the former.

In a similar manner as PAOs, DNPAOs take up external carbon substrates and store as polyhydroxyalkanoates (PHAs) in the cell under anaerobic conditions. However, they can utilize nitrite or nitrate instead of oxygen as an electron acceptor to remove phosphorus without any additional carbon source under anoxic conditions. Based on the principle that phosphorus uptake was greater than phosphorus release, the discharge of excess sludge can achieve the purpose of simultaneous nitrogen and phosphorus removal [2].

\section{Status of Enrichment of Denitrifying Phosphorus Removal Bacteria in Different Processes}

For the past few years, many scholars coupled different processes of nitrogen and phosphorus removal and denitrifying phosphorus removal technology, domesticate and enrich DNPAOs in the conventional processes of nitrogen and phosphorus removal to further improving the efficiency of nitrogen and phosphorus removal. Universally, PAOs always exist in nitrogen and phosphorus removal process of municipal waste water treatment plants, DNPAOs is actually a part of PAOs, but the amount was limited[3]. And the key of a stable operation of denitrifying phosphorus removal system is domestication and enrichment of DNPAOs in the system. From analysis of the mechanism of biological denitrification and phosphorus removal, the process of biological nitrogen and phosphorus removal basically can be divided into three states: anaerobic, anoxic and aerobic. These three different working states can be separated in space, also can be separated in time.

Process of Nitrogen and Phosphorus Removal in Spatial Sequence. The primary characteristic of nitrogen and phosphorus removal process of spatial sequence is completing a series of biological reactions in different reaction tank at the same time. The typical process is Anaerobic-Anoxic-Oxic process $\left(\mathrm{A}^{2} / \mathrm{O}\right)$, which occupies more than $50 \%$ share of nitrogen and phosphorus removal process market in China, so it is the capital process of domestic sewage treatment plant. In order to achieve more efficient nitrogen and phosphorus removal efficiency in $\mathrm{A}^{2} / \mathrm{O}$, many scholars took denitrifying phosphorus removal technology as a part of $\mathrm{A}^{2} / \mathrm{O}$ technology, enriched DNPAOs in $\mathrm{A}^{2} / \mathrm{O}$ process.

Cao Xuemei [4] did a series of experiments in a 52 $\mathrm{L} \mathrm{A}^{2} / \mathrm{O}$ reactor, by changing aerobic nitrification liquid reflux ratio (300\%) increase nitrate nitrogen concentration in the anoxic zone to stimulate enrichment of DNPAOs, the anoxic phosphorus removal has reached 69\%; by increasing volume ratio of anoxic zone to aerobic zone to enhance the anoxic water residence time and improve the proportion of DNPAOs in the system.

Jiang Lv et al. [5] confirmed that appropriate extension of sludge age is helpful for DNPAOs to removal phosphorus in $\mathrm{A}^{2} / \mathrm{O}$ system. Longer SRT (10 days) made DNPAOs slow-growing and small-reproduction in anoxic stage because there were not enough external carbon sources. So in the competition of living environment between denitrifying bacteria and denitrifying phosphorus bacteria, denitrifying bacteria at a disadvantage. And the best effect of denitrification occurs in this phenomenon that the proportion of anti nitrification and phosphorus accumulating bacteria reached $46.1 \%$.

In $\mathrm{A}^{2} / \mathrm{O}$ process Wang Xiaolian[6]also confirmed that when anoxic effluent nitrate concentration controlled in $1 \sim 3 \mathrm{mg} / \mathrm{L}$ and the corresponding internal recirculation ratio was 3 to 3.5 , the $\mathrm{A}^{2} / \mathrm{O}$ process could be significantly denitrifying phosphorus removal. At this time the contribution of denitrifying phosphorus removal to the whole process of phosphorus removal was the largest. This operating condition not only promoted accumulation and growth of DNPAOs, and due to the contribution of denitrifying phosphorus removal in whole process of phosphorus removal, aeration rate in aerobic zone reduced from $400 \mathrm{~L} / \mathrm{h}$ to $320 \mathrm{~L} / \mathrm{h}$, thus saved the amount of aeration and reduced energy consumption of aeration.

According to the theory and research actuality of denitrifying phosphorus removal, it can enhance denitrifying phosphorus removal performance by changing the following parameters of $\mathrm{A}^{2} / \mathrm{O}$ process, including increasing internal reflux ratio and providing sufficient electron receptor to stimulate enrichment and growth of denitrifying phosphate-accumulating organisms; optimization of 
anaerobic/anoxic/aerobic volume ratio, enhancing HRT of anoxic zone to complete denitrifying and phosphorus accumulation fully; changing the sludge age to make the activity of DNPAOs reach the maximum, and so on. Through the above methods, $\mathrm{A}^{2} / \mathrm{O}$ has achieved higher efficiency for simultaneous nitrogen and phosphorus removal. $\mathrm{A}^{2} / \mathrm{O}$ technology as the main way to removal nitrogen and phosphorus at the present stage is still the most commonly core process of sewage treatment plant in China. With the standards of China's sewage discharge have became more and more strict, enrichment of DNPAOs by controlling the operation parameters in $\mathrm{A}^{2} / \mathrm{O}$ process become more and more popular and to achieve high efficiency and stability of nitrogen and phosphorus removal by using the technology of denitrification and phosphorus removal for water entrophication has very important practical significance.

Process of Nitrogen and Phosphorus Removal in Time Sequence. The biggest feature of biological phosphorus and nitrogen removal technology in time sequence is various sewage biochemical reactions in the same reaction tank, sewage treatment according to the time sequence. One of the most typical processes is the sequencing batch reactor activated sludge process (SBR). SBR process, thanks to its simplicity, to its operating flexibility and low capital expenditure, has been widely used in the study about denitrifying phosphorus removal the whole world in recent years.

Li Zhiyong [7] using SBR reactor, through anaerobic/aerobic and anaerobic/precipitation drainage/ anoxic, anaerobic / hypoxia acclimated denitrifying phosphorus accumulating bacteria. The second stage anaerobic/precipitation drainage/hypoxia was the key, by precipitation drainage, so as to avoid residual COD and nitrate coexist in anoxic zone, which adversely affect efficiency of denitrifying phosphorus removal. The proportion of DNPAOs increased from $15.5 \%$ to $73 \%$ of total phosphate accumulating organisms after three phase selection. The concentration of phosphorus at anoxic end was low than $1 \mathrm{mg} / \mathrm{L}$ and phosphorus and nitrate removal efficiency were above $94 \%$ and $95 \%$ respectively.

By controlling the nitrate concentration in the anoxic stage, Zhang Xiaoling [8] studied the methods and effects of inducing DNPAOs. The results of the batch experiments prove that with the same carbon source, a linear relationship between the quantity of phosphorus uptake and the consumption of nitrate is shown under anoxic condition, and the line slope was equal to the ratio between phosphorus re lease quantity and nitrate consumption. During inducing the DNPAOs, adjusting nitrate concentration based on this ratio can rapidly reach an excellent effect of nitrogen and phosphorus removal: the removal efficiencies of phosphorus and nitrogen are above $95 \%$ and $96 \%$, respectively. By calculating the maximum anoxic or aerobic phosphorus uptake rate under the same conditions, the percent of DNPAOs after cultivation increased from $27.61 \%$ to $78.61 \%$.

In Satoshi Tsuneda's study [9], an anaerobic/aerobic/anoxic process using SBR was proposed for simultaneous phosphorus and nitrogen removal from wastewater. In the SBR, PHAs was synthesized by using external carbon source in anaerobic phase, a certain amount of carbon substrate (20-40 $\mathrm{mg}-\mathrm{C} / \mathrm{L}$ ) was supplemented at the start of aerobic conditions to temporally inhibit aerobic phosphorus uptake, and ammonia oxidation provided nitrate nitrogen and nitrite nitrogen as electron acceptor for denitrifying phosphorus removal in the anoxic phase. This mode omitted the internal recirculation between aerobic and anoxic and achieved ammonia oxidizing and denitrifying phosphorus removal in a single reactor. The test results showed that in the AOA-SBR process the fraction of DNPAOs with respect to total PAOs was $44 \%$. The average nitrogen and phosphorus removal efficiencies were $83 \%$ and $92 \%$, respectively.

In SBR, many scholars have done a great many researches about different alternation patterns and feed modes on enrichment of denitrifying phosphorus accumulating bacteria. Despite the enrichment modes and degree of enrichment was different, the main way of denitrifying phosphorus accumulating bacteria enriched in SBR was the alternation of anaerobic and anoxic environment. DNPAOs in anaerobic stage used external carbon source for the synthesis of a sufficient amount of PHAs, in the anoxic denitrifying phosphorus accumulating bacteria was induced by adding enough nitrate as denitrifying phosphorus electron acceptor. Similar to $\mathrm{A}^{2} / \mathrm{O}$ process, the key of the enrichment is to avoid the coexistence of carbon source and nitrate in the same environment. The existence of nitrate in 
anaerobic stage will make ordinary denitrifying bacteria using carbon source for denitrification preferentially, and competition of carbon source between ordinary denitrifying bacteria and DNPAOs, which has adverse effects on the use of carbon source to synthesize PHAs by DNPAOs. External carbon source in anoxic stage also can make ordinary denitrifying bacteria preferentially utilize nitrate denitrification which affects denitrifying phosphorus removal. Therefore, various measures must be taken to avoid the coexistence of $\mathrm{N}$ and $\mathrm{C}$. Likewise new SBR processes which use denitrifying phosphorus removal technology provide new ideas to improve traditional processes of nitrogen and phosphorus removal.

\section{Conclusions}

At present, the study of denitrifying phosphorus removal technology has achieved initial results at home and abroad, and the technology of denitrifying phosphorus removal is developing from basic research to engineering application. Biological mechanism of denitrifying phosphorus removal and single operation parameter of process were done a more in-depth study, but the study about comprehensive effect of many factors is still less. Little is known about the structure and function of microbial community in the denitrifying phosphorus removal system. We can do the isolation, screening and identification for the pure culture DNPAOs by using biology technology, do further analysis about the mechanism of nitrogen and phosphorus removal and reveal the relationship between species group structure and function. At the same time, the application of online detection technology and mathematical model can further improve its controllability of the denitrifying phosphorus removal process.

\section{Acknowledgements}

This study was partly supported by National Natural Science Foundation of China (51278225), Shandong Provincial Natural Science Foundation, China (ZR2013EEQ007, ZR2015EM021).

\section{References}

[1] T. Kuba, G. Smolders, M. C .M .V Loosdrecht, et al: Waterence \& Technology Vol. 27(1993), p.241.

[2] A.G.Kapagiannidis, I.Zafiriadis, A.Aivasidis: Water Science \& Technology Vol. 60 (2009), p.2695.

[3] J. Meinhold, C.D.M.Filipe, G.T.Daigger, et al: Water Science \& Technology Vol. 39(1999), p.31.

[4] Xuemei Cao. Master thesis: Harbin Institute of Technology, 2007. In Chinese.

[5]Jiang Lv, Shaoqi Zhou, Weifeng Wang, et al: Environmental Science \& Technology Vol. 34(2011), p.45. In Chinese.

[6] Xiaolian Wang, Shuying Wang, Yayi Wang et al: Acta Scientiae Circumstantiae Vol.26 (2006), p.722.In Chinese.

[7] Yongzhi Li,Shuying Wang,FansongWu, et al: Acta Scientiae Circumstantiae Vol. 24(2004), p.45. In Chinese.

[8] Xiaoling Zhang, Liqing Zhang, Linjiang Yuan, et al: China Water \& Wastewater Vol. 22(2006), p.105. In Chinese.

[9] S. Tsuneda, T. Ohno, K. Soejima, A. Hirata, et al: Biochemical Engineering Journal Vol. 27(2006), p.191. 